\title{
The Adoption OF MOdeRn TeChNOLOGY SPECIFIC TO INDUSTRY 4.0 BY HUMAN FACTOR
}

\author{
Iva Mikulić \& Anja Štefanić
}
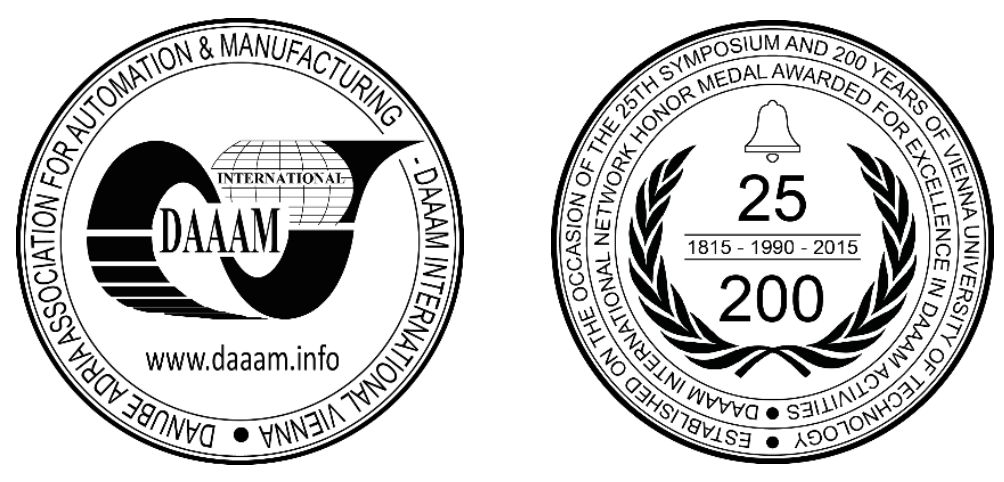

This Publication has to be referred as: Mikulic, I[va] \& Stefanic, A[nja] (2018). The Adoption of Modern Technology Specific to Industry 4.0 by Human Factor, Proceedings of the 29th DAAAM International Symposium, pp.0941-0946, B. Katalinic (Ed.), Published by DAAAM International, ISBN 978-3-902734-20-4, ISSN 1726-9679, Vienna, Austria DOI: $10.2507 / 29$ th.daaam.proceedings.135

\begin{abstract}
The digitalization of business and correspondingly processes is surely becoming a requirement for successful organizations and companies within different industries, mainly in order to remain competitive. That emphasizes importance of new ideas and innovations that could even more enhance and improve current processes. The concept of Industry 4.0 represents a development and usage of technology that is alternating traditional industries. However, even that nowadays is not difficult to implement such technologies, the success of implementation depends mostly on accepting changes by employees. This paper presents an approach for easy identification of advantages and disadvantages of modern technology application considering their impact on human factor within the process, as employees are the most important factor in processes. Moreover, it suggests intersection of the lean concept with industry 4.0 in order to improve the process regarding the human factor at the very beginning of industry 4.0 technology implementation.
\end{abstract}

Keywords: Industry 4.0; human factor; lean concept; modern technology

\section{Introduction}

Today, due to the high competition and customer demand, there is no longer mentioning of mass production. Production is reduced to the delivery of products tailored by customer demand. Production and process management in such conditions require new approaches and the use of new technologies to maximize system productivity and efficiency.

The globalization trends of this crisis that has emerged over the last years has put science at the forefront of new challenges in utilizing existing resources (Internet, smartphones...) to improve production and service systems in manufacturing, healthcare, services, etc. New concepts such as smart factory, Cyber - Physical System, Internet of Things, smart products, smart technologies are developing in a fast way. So it can be said that a new industrial revolution known as Industry 4.0 has begun.

The "4.0" refers to the fourth industrial revolution. The first industrial revolution was the utilization of machines, the second involved assembly lines and mass production, the third employing automation, and now the fourth industrial revolution: cyber physical systems (machines communicating with one another), as shown in Fig. 1. 


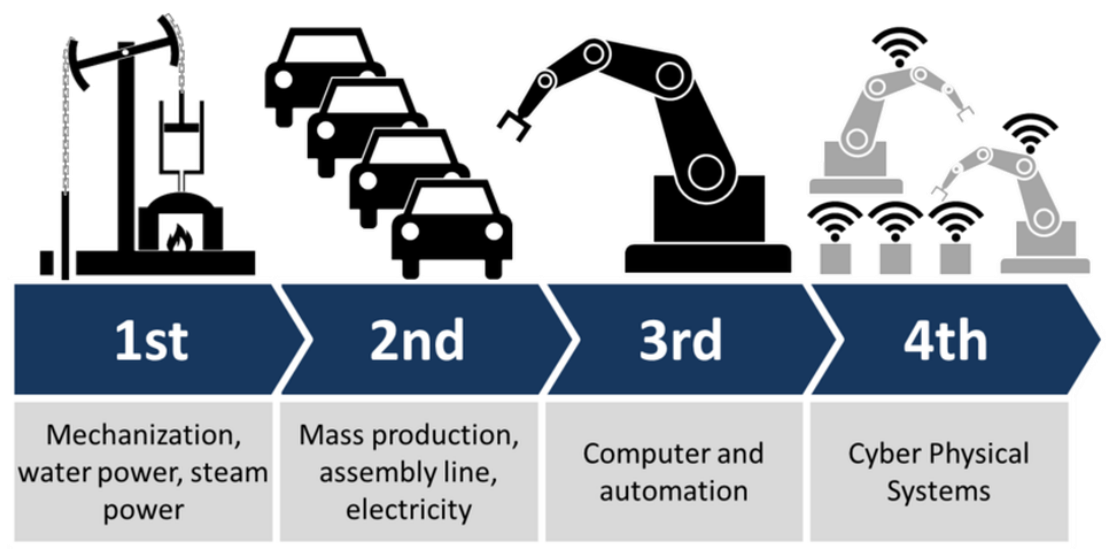

Fig. 1. The 4 Industrial Revolutions (by Christoph Roser at AllAboutLean.com) [1]

Stepping into 4th Industrial revolution has pushed companies to embrace new technologies in order to successfully fulfill customer's demands for high quality and value-added products. In manufacturing, using new technologies results in time saving, smart components, smart products, real time following of the product, transparency, the availability of information, new software possibilities, higher data security... These are just a few results of adopting and using the new technologies in companies. Everything that is mentioned sounds appealing, but what about the fact how technology will be used, who will use it and how?

Step between creating a new technology and implementing it in companies are people who have to adapt to the technology and prepare the processes for it before the implementation. The human factor is highly important and it presents a certain risk. That is why it is important to discover the obstacles in adopting new technologies in order to deal with them and neutralize them.

\section{Literature Review}

The concept of Industry 4.0 represents a development that is alternating traditional industries. In recent years, the importance of Industry 4.0 is increasing, especially in successful European manufacturing companies. The authors in [2] used state-of-the-art research in the field of industry 4.0 and service network in order to create an interdisciplinary model based on different scientific approaches that is flexible enough to be applied to various different business views and strategies. The authors in [3] have emphasized advantages of using analytics and business intelligence as important industry 4.0 techniques in the case of brush manufacturing. This approach allows even non-experts to make quick and effective decisions in critical situations, such as delayed delivery. The application of industrial engineering tools to the food service business has proven to be successful in enhancing efficiency, productivity and profit of an organization, as shown in [4].

Nedomlelova et al. in [5] emphasized four factors that are crucial for Industry 4.0 implementation that consider research, development and innovation, human resources, education, and infrastructure. In order to achieve adequate process for new technology introduction, it is necessary to analyze the process first. That implies the application of lean concept. The relation between industry 4.0 and Lean management is emphasized in [6], where a project called Innovative Smart Enterprise was conducted in order to improve scientific understanding of the actual Croatian manufacturing industry. Even that the progress of the concept of Industry 4.0 is very slow, it provides a great base for future research in the area of service industry in Croatia. The research shown in [7] established that the Industry 4.0 is not applicable in Croatian industry, which is mainly a consequence of a poor employee training program.

However, the key factors for achieving such results are commitment and understanding of the staff, i.e., human resources. In accordance with this, the authors in [8] state that staff's resistance to changes is the largest challenge and problem in lean management application. Although present in the production sector, it is more prominent in the service industry because the largest part of the work is done by people. The research under [9] has used a two-year case study in a Norwegian company and concluded that change is perceived differently at various hierarchical levels, which then creates impediments to the implementation of the lean tool. The ability to recognise and solve these hurdles can enable successful lean technique application within various organisations.

Brauner et al. [10] have emphasized that modern technology implementation cause changes in conventional processes. The greatest challenge is human factors that have to adapt and process complex technology and data which is the problem for greying society. The paper proposes removing barriers by integration of human factor within the technology development which is a great solution for dealing with problems regarding technology adoption. The authors in [11] deal with psychosocial risk assessment because modern technology application causes new stressors. Determination of possible stressor is crucial for providing the basis for identification of possible problems connected to technology adoption. Samaranayake et al. in their paper [12] confirm the importance of various factors from a technological readiness perspective when implementing Industry 4.0 technologies. 
This research only pointed a perspective regarding technological readiness, but the main limitation is that human readiness was not considered as a factor affecting successful Industry 4.0 implementation within organizations. According to [13]: "The idea behind this "4th industrial revolution" is to connect all elements of the value chain process into one single system". However, the human factor is often left out, although it has to adapt to new technology and acquire new skills. The solution is inclusion of human factors in all phases of designing and technology implementation.

The working environment is rapidly changing, according to [14]. The paper considers both technological and human improvements that affect greater productivity and process improvement. It implies that certain professions are gaining the other dimensions and various difficulties that older working force is facing. However, to perceive greater perspective on Industry 4.0 the need is to identify all problems that the human factor as employees within the process are facing during technological convergence. Likewise, the paper [15] present a human-centered approach as an advantage within Industry 4.0 concept unlike techno-centered approach.

Authors propose designing and evaluating systems in organizations and emphasize their interactions with humans by using Artificial Self-Organizing systems (ASO) as an example. Results of the research have emphasized that humancentered approach improves performance in terms of energy consumption. The requirement of substantial employees' skills for operation with advanced machines in various activities within process is emphasized in [16]. The authors proposed the development of Augmented reality (AR)-based assistance systems for successful implementation of modern technologies. However, that presents the challenge regarding high cost especially. On the other hand, the alternative is introduction of standardized procedures.

Literature review, which was carried out within the scope of this paper, leads to conclude that the field of the industry 4.0 implementation as the field of research abounds with papers, particularly in the last two years. Researches gave an insight into industry 4.0 implementation in organizations, with a special emphasis on the main issue, the lack of human factor perspective. In addition, most papers present an approach regarding successful technological application, while there is a shortage of an approach concerning modern technology adoption from employees as human factor in processes. The aim of this research is to consider all possible problems that are present when adopting modern technologies by their users.

\section{Method}

In order to establish the model for successful industry 4.0 implementation, it is important to consider all perspectives, both technological and human. Moreover, at the very beginning of the modern technology application within the process, it is important to consider the process itself within the process analysis. This research proposes the first step which refers to identification of all barriers which prevent the successful adoption of modern technology by a human factor.

The literature review was used as the basis for the creation of possible problems of modern technology adoption by human factors. Problems are identified as follows:

- The lack of standardized instructions for using modern technology: The creation and use of standardized instructions within various organizations is not a novelty, however there is a great need for them regarding a modern devices application by employees. This is above all necessary for providing safe and precise operation. Inadequate professional instructions may cause errors, injuries, malfunctions etc.

- The lack of previous training: A large number of employees who are confronted with complex modern technology often do not have the adequate knowledge and are of older age. For this reason, it is more difficult for them to adapt to changes in the workplace. The appropriate solution would allow them a larger number of previous training to learn everything crucial for successful work.

- Insufficient quantity of adequate equipment: Although many organizations strive for successful adoption of modern systems, they often do not carry out their work by providing employees with all necessary equipment and spare parts when it comes to malfunctions.

- The fear of errors: Even that "to err is human", most employees at the very beginning of the innovations application consider their error as a personal failure which is quite discouraging for their performance.

- The fear of repercussions: Regarding the fear of errors, that fear is a cause-effect connected with the fear of the consequences. Employees are afraid of making an error, so as not to get penalties, discouragement or ultimately dismissal. Also, depending on the work area, there is a fear of how the error would affect other parts and participants within the process.

- Technical issues of the system and dealing with them: When changes occur within a single process, the fact is that it is possible to expect breakdowns and delays, especially at the beginning of the application. Employees are mostly worried about how they will cope with these failures. 
- The fear of changes: The introduction of modern technology is not the only segment that causes fear and resistance to change. Any change that affects the habit change results with fear, and fear causes resistance. The biggest fear is that employees will not succeed in adopting the novelties and will error often.

To determine which of the above mentioned is more important, the survey was conducted. For research purposes, the survey was filled by 30 people. The age of people who participated is from 28 years to 60 years. Out of all respondents, $80 \%$ are men and $20 \%$ are women. As far as education is concerned, people who have completed high school or college have participated. Another important fact is that they work in a workplace that requires the adoption of modern technology. The survey consisted of two questions. The first question was focused on the subjective assessment of the modern technology adoption complexity in the workplace. Furthermore, the second question has taken into account previously identified problems in determining the largest and the most common one among respondents. The goal was to determine which is of utmost importance for technology inherent to industry 4.0 implementation.

First question: "Do you find it difficult to adopt modern technology in your everyday work?"

1 very difficult

2 difficult

3 neutral

4 easy

5 very easy

Second question: "Rank with numbers from 1 to 7 which is in your opinion the biggest reason of more difficult modern technology adoption, where 1 is the smallest and 7 the biggest reason of the listed below."

The lack of standardized instructions for using modern technology

The lack of previous training

Insufficient quantity of adequate equipment

The fear of errors

The fear of repercussions

Technical issues of the system and dealing with them

The fear of changes

After the survey was conducted, the results were analysed and discussed in order to determine which is the main critical point while implementing Industry 4.0 technologies within processes and organizations. The results and discussion are shown in continuation.

\section{Result and Discussion}

Difficulty of adopting modern technology was the first question that respondents had to answer. Results show that $46 \%$ of respondents find it easy to adopt modern technology. Furthermore, $27 \%$ of respondents do not find it difficult or easy to adopt modern technology, they stayed neutral while answering the question. It is interesting that an equal number of people find it very difficult $(9 \%)$, difficult $(9 \%)$ and very easy $(9 \%)$ to adopt modern technology.

If two results for "easy" (46\%) and "very easy" (9\%) are summed up, total result of 55\% suggest that generally respondents do not have problems with modern technology but on the contrary they easily adopt it. Results are shown below (Fig. 2.).

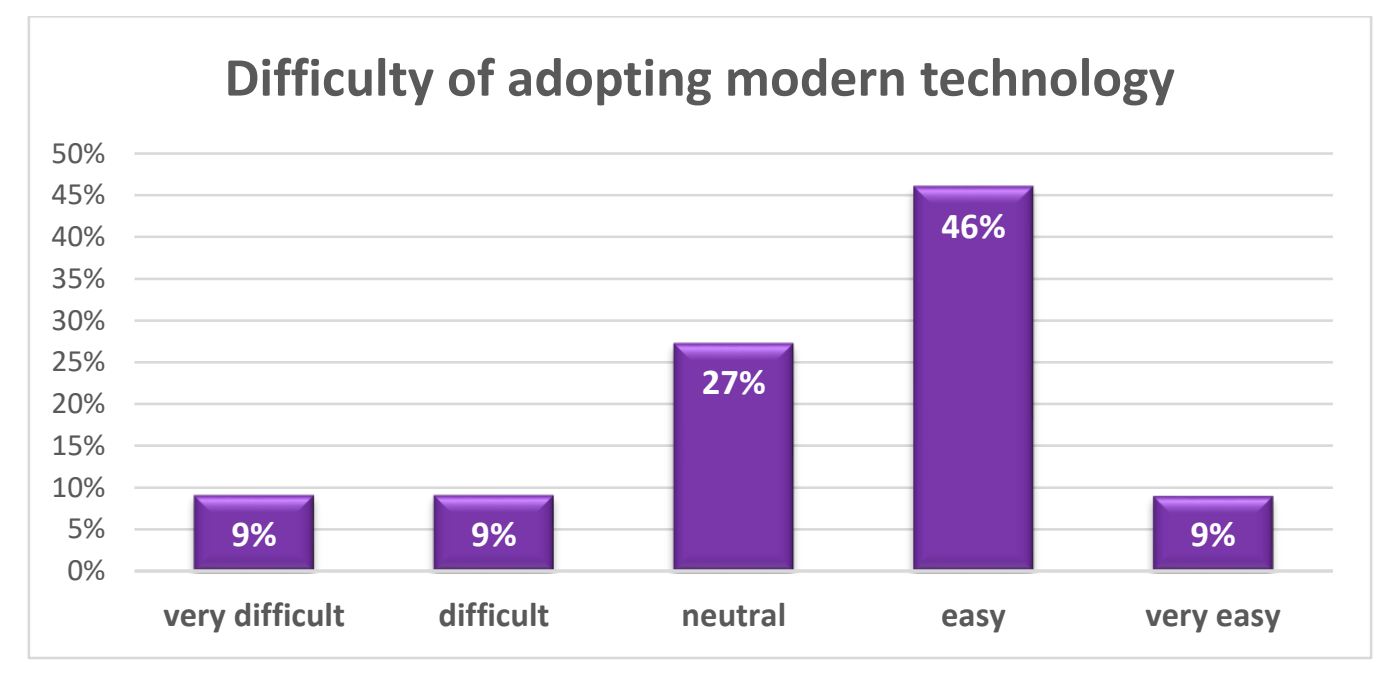

Fig. 2. Difficulty of adopting modern technology 
Even tough majority of respondents easily adopt modern technology, barriers that prevent the successful adoption of modern technology can occur during that process. That is why respondents had to rank problems from the biggest reason (assign number 7 to that problem) to the smallest reason (assign number 1 to that problem) of more difficult modern technology adoption.

Results (Fig. 3.) show that the biggest reason for difficult modern technology adoption are technical issues (rank 5) and the lack of standardized instructions (rank 5) for using modern technology. Respondents find it much less difficult to deal with fear of repercussions (rank 3) or with insufficient quantity of adequate equipment (rank 3). The fear of changes has the same rank number 4 along with the fear of errors and the lack of previous training.

\section{Problems of modern technology adoption by human factor}

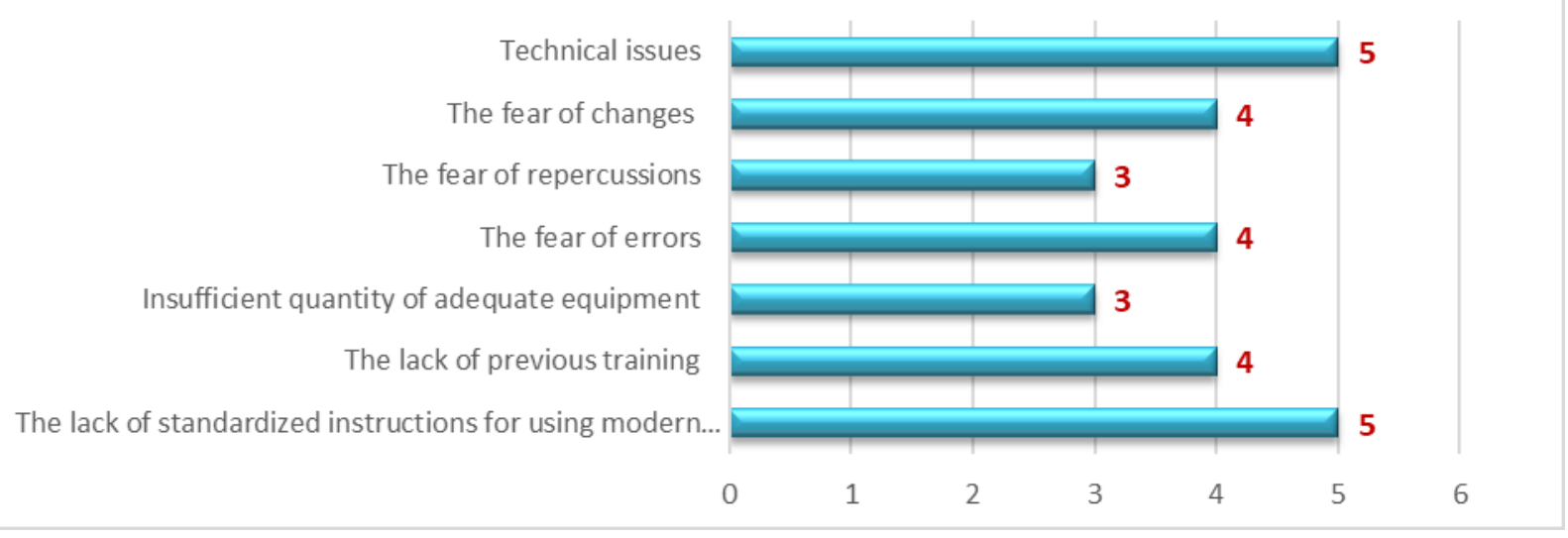

Fig. 3. Problems of modern technology adoption by human factor

Taking into consideration that all problems mention above can be solved by making standardized instructions, more specialized training, introducing new politics in the companies that will encourage people instead of scaring them, why are modern technologies taboo topic for many people. During the analysis, the deeper problem is a lack of proper methodology that will ensure transparency and standard procedure as well as proper communication in companies.

\section{Conclusion}

The aim of this research was to emphasize the importance of human factor regarding Industry 4.0 implementation within various processes and organizations by considering all possible problems due to modern technology adoption by their users, in order to propose a model for successful Industry 4.0 introduction. The literature review has shown that many papers are investigating readiness for Industry 4.0 as well as the lack of the human factor involved regarding the modern technology application. However, only few of them identify possible problems and propose a solution for dealing with lack of human factor involvement.

According to conducted research, it was easy to identify advantages and disadvantages of modern technology adoption by human perspective. It is evident that modern technology provides many benefits both for the process and for a human factor within it as a process participant. It refers to the process acceleration and facilitation that are increasing efficiency of the process, which finally results with increasing employee efficiency and satisfaction as well. On the other hand, if employees are not educated and untrained it will be quite difficult to deal with usage of complex hi-tech equipment, machines and systems. This represents a challenge for human resources management as well because adequate skills will become much more important.

The Results of the research provided an insight that the lack of standardized instructions and possible technical issues are main problems when applying modern technologies within the process. The best way to solve these problems is to involve employees, that will be end-users, in technology design. That will provide successful technology adoption. However, even that $55 \%$ of the respondents find it easy to adopt modern technology, research limitations refer to a small number of respondents and the fact that Croatian industry has not yet applied complex technology inherent to Industry 4.0. All identified barriers for successful modern technology adoption are present and often established. On the one hand, identifying them will enable better process and preparation of all necessary activities regarding waste elimination and enabling the successful application and adoption of modern technology by the user. In addition, that ultimately results in the process improvement. On the other hand, if identified potential problems are not taken into account, not only does the success and quality of the process activities performance decrease, but also the employee's revolt can be caused due to insecurity and dissatisfaction. 
Proposed human-oriented perspective regarding identification of the problems within the process would enable successful technology adoption and modernization of organizations. Furthermore, it will propose a basis for designing a model that will enable successful modern technology implementation and will address all above mentioned problems. Many problems can be solved by introducing a lean concept which tools and methods allow to identify and eliminate all critical points, i.e. waste within the process. The second step of the future research will focus on the detailed identification of all obstacles to the introduction of the industry 4.0 concept, beside human factor adoption, and its distinctive modern technology, considering all perspectives and proposing a model for solving it.

\section{Acknowledgments}

We would like to thank all survey participants for their time and provided answers.

\section{References}

[1] https://www.allaboutlean.com/industry-4-0/, (2015). Roser, C., A critical look on Industry 4.0| AllAboutLean.com, Accessed on: 2018-05-03

[2] Rennung, F.; Luminosu, C.T. \& Draghici, A. (2016). Service Provision in the Framework of Industry 4.0, 13th International Symposium in Management: Management During and after the Economic Crisis 221, 372-377.

[3] Neubock, T. \& Schrefl, M. (2015). Modelling Knowledge about Data Analysis Processes in Manufacturing, Ifac Papersonline 48(3), 277-282.

[4] Martinez, J. (2010). Doing it your way, Industrial Engineer 42(3), 28-33.

[5] Nedomlelova, I. \& Werner, J. (2017). Readiness of the Usti nad Labem Region for the Implementation of the Industry 4.0 Concept

[6] Veza, I.; Mladineo, M. \& Gjeldum, N. (2016). Selection of the basic lean tools for development of croatian model of innovative smart enterprise, Tehnicki Vjesnik-Technical Gazette 23(5), 1317-1324.

[7] Stojkić, Ž.; Veža, I. \& Bošnjak, I. (2015). A concept of information system implementation (crmand erp) within industry 4.0, Annals of DAAAM and Proceedings of the International DAAAM Symposium, pp. 912-919.

[8] Vignesh, V., Suresh, M. \& Aramvalarthan, S. (2016). Lean in service industries: A literature review, IOP Conference Series: Materials Science and Engineering

[9] Lodgaard, E.; Ingvaldsen, J.A.; Gamme, I. \& Aschehoug, S. (2016). Barriers to Lean Implementation: Perceptions of Top Managers, Middle Managers and Workers, Procedia CIRP, pp. 595-600.

[10] Brauner, P. \& Ziefle, M. (2015). Human Factors in Production Systems Motives, Methods and Beyond, in: C. Brecher (Ed.), Advances in Production Technology, pp. 187-199.

[11] Diebig, M.; Jungmann, F.; Muller A. \& Wulf I.C. (2018). Challenges for Psychosocial Risk Assessment During the Digital Transformation of Industry: A Qualitative Interview Study, Zeitschrift Fur Arbeits-Und Organisationspsychologie 62(2), 53-67.

[12] Samaranayake, P.; Ramanathan, K. \& Laosirihongthong, T. (2017). Ieee, Implementing Industry 4.0-A Technological Readiness Perspective, Ieee International Conference on Industrial Engineering and Engineering Management2017, pp. 529-533.

[13] Kinzel, H. (2017). Industry 4.0 - Where Does This Leave the Human Factor?, Journal of Urban Culture Research $15,70-83$.

[14] Trstenjak, M.; Cosic, P. (2017). Process planning in Industry 4.0 environment, in: M. Pellicciari, M. Peruzzini (Eds.), 27th International Conference on Flexible Automation and Intelligent Manufacturing, Faim2017, pp. 1744-1750.

[15] Pacaux-Lemoine, M.P.; Trentesaux, D.; Rey, G.Z. \& Millot, P. (2017). Designing intelligent manufacturing systems through Human-Machine Cooperation principles: A human-centered approach, Computers \& Industrial Engineering $111,581-595$

[16] Kerpen, D.; Lohrer, M.; Saggiomo, M.; Kemper, M.; Lemm, J. \& Gloy, Y.S. (2016). Ieee, Effects of Cyber-Physical Production Systems on Human Factors in a Weaving Mill Implementation of Digital Working Environments based on Augmented reality, Proceedings 2016 Ieee International Conference on Industrial Technology (Icit), 2094-2098. 